Article

\title{
Irradiation by a Combination of Different Peak-Wavelength Ultraviolet-Light Emitting Diodes Enhances the Inactivation of Influenza A Viruses
}

\author{
Mizuki Kojima ${ }^{1,+}{ }^{,}$Kazuaki Mawatari ${ }^{1, *,+}+\mathbb{C}$, Takahiro Emoto ${ }^{2,+}$, Risa Nishisaka-Nonaka ${ }^{1}$, \\ Thi Kim Ngan Bui ${ }^{1}$, Takaaki Shimohata ${ }^{1}$, Takashi Uebanso ${ }^{1}$, Masatake Akutagawa ${ }^{2}$, \\ Yohsuke Kinouchi ${ }^{2}$, Takahiro Wada ${ }^{3}$, Masayuki Okamoto ${ }^{3}$, Hiroshi Ito ${ }^{3}$, Kenji Tojo ${ }^{3}$, \\ Tomo Daidoji ${ }^{4}$, Takaaki Nakaya ${ }^{4}(1)$ and Akira Takahashi ${ }^{1}$ \\ 1 Department of Preventive Environment and Nutrition, Institute of Biomedical Sciences, Tokushima \\ University Graduate School, Kuramoto-cho 3-18-15, Tokushima City, Tokushima 770-8503, Japan; \\ mizugojira@gmail.com (M.K.); st_2r_flight062b@yahoo.co.jp (R.N.-N.); \\ kimnganvdd1190@gmail.com (T.K.N.B.); shimohata@tokushima-u.ac.jp (T.S.); \\ uebanso@tokushima-u.ac.jp (T.U.); akiratak@tokushima-u.ac.jp (A.T.) \\ 2 Graduate School of Technology, Industrial and Social Sciences, Minamijyousanjima-cho 2-1, Tokushima City, \\ Tokushima 770-8506, Japan; emoto@tokushima-u.ac.jp (T.E.); makutaga@tokushima-u.ac.jp (M.A.); \\ kinouchi@tokushima-u.ac.jp (Y.K.) \\ 3 Nihon Funen Co., Ltd., 179-1 Mitsujima-shinden, Kawashima-cho, Yoshinogawa City, Tokushima 779-3394, \\ Japan.; t-wada@nihonfunen.co.jp (T.W.); okamoto@nihonfunen.co.jp (M.O.); ito@nihonfunen.co.jp (H.I.); \\ tojyo@nihonfunen.co.jp (K.T.) \\ 4 Department of Infectious Diseases, Graduate School of Medical Science, Kyoto Prefectural University of \\ Medicine, 465 Kajii-cho, Kawaramachi-Hirokoji, Kamigyo-ku, Kyoto 602-8566, Japan; \\ daidoji@koto.kpu-m.ac.jp (T.D.); tnakaya@koto.kpu-m.ac.jp (T.N.) \\ * Correspondence: mawatari@tokushima-u.ac.jp; Tel.: +81-88-633-9598 \\ $\dagger$ These authors contributed equally to this work.
}

Received: 29 May 2020; Accepted: 6 July 2020; Published: 8 July 2020

Abstract: Influenza A viruses (IAVs) pose a serious global threat to humans and their livestock. This study aimed to determine the ideal irradiation by ultraviolet-light emitting diodes (UV-LEDs) for IAV disinfection. We irradiated the IAV H1N1 subtype with $4.8 \mathrm{~mJ} / \mathrm{cm}^{2} \mathrm{UV}$ using eight UV-LEDs [peak wavelengths $(\mathrm{WL})=365,310,300,290,280,270$, and $260 \mathrm{~nm})$ ] or a mercury low pressure (LP)-UV lamp (Peak WL $=254 \mathrm{~nm}$ ). Inactivation was evaluated by the infection ratio of Madin-Darby canine kidney (MDCK) cells or chicken embryonated eggs. Irradiation by the $260 \mathrm{~nm}$ UV-LED showed the highest inactivation among all treatments. Because the irradiation-induced inactivation effects strongly correlated with damage to viral RNA, we calculated the correlation coefficient $\left(R_{\mathrm{AE}}\right)$ between the irradiant spectrum and absorption of viral RNA. The $R_{\mathrm{AE}}$ scores strongly correlated with the inactivation by the UV-LEDs and LP-UV lamp. To increase the $R_{\mathrm{AE}}$ score, we combined three different peak WL UV-LEDs (hybrid UV-LED). The hybrid UV-LED $\left(R_{\mathrm{AE}}=86.3\right)$ significantly inactivated both $\mathrm{H} 1 \mathrm{~N} 1$ and $\mathrm{H} 6 \mathrm{~N} 2$ subtypes to a greater extent than $260 \mathrm{~nm}\left(R_{\mathrm{AE}}=68.6\right)$ or $270 \mathrm{~nm}$ $\left(R_{\mathrm{AE}}=42.2\right)$ UV-LEDs. The $R_{\mathrm{AE}}$ score is an important factor for increasing the virucidal effects of UV-LED irradiation.

Keywords: light emitting diode; ultraviolet; influenza A virus

\section{Introduction}

Influenza viruses are enveloped viruses whose genome consists of segmented negative-sense single-strand RNA segments. There are four types of influenza viruses, including A, B, C and D, and 
types A and B show epidemic spread. Influenza A viruses (IAVs) are encircled by the M1 matrix protein and a host-derived lipid bilayer envelope in which the virus surface glycoproteins hemagglutinin (HA) and neuraminidase (NA), as well as the M2 matrix protein, are embedded [1]. HA and NA play critical roles in viral entry into host cells and release from the cells, respectively [2]. IAVs bind to sialic acid molecules, such as $\alpha 2,6$-linked sialo-glycans (SA $\alpha 2,6)$, which are abundant in the human upper respiratory tract [3]. Following internalization, receptor-bound viruses are delivered to endosomes, and upon acidification, HAs are activated to fuse the virus and endosomal membranes [4]. NA cleaves the sialic acid molecule, thereby freeing the virus and allowing it to infect other cells in the host organism.

IAVs exhibit zoonotic potential because novel IAV mutants frequently emerge and are able to cross species barriers. Therefore, IAV infections are a globally important issue not only in humans but also in their livestock. Avian influenza (AI) viruses are classified by their pathogenic strength based on the feasibility of infection in chickens [5]. The critical genetic difference determining the low pathogenic (LPAI) or highly pathogenic (HPAI) phenotype depends on the HA cleavage site [6]. HPAI viruses, such as H5N1 and H7N9, have only two HA subtypes, including H5 and H7 [6]. In addition to infecting chickens, H5N1 subtypes emerged as a human pathogen in 1997 with the expected potential to undergo sustained human-to-human transmission and pandemic viral spread [7]. LPAI H6 subtypes have a broader host range than any other IAV subtype [8] and are suggested to be involved in the generation of human H5N1, H9N2, and H5N6 subtypes [7,9]. H6 subtype reassortment viruses might have crossed the species barrier and infected mammals, including humans, without adaptation. Recent seroprevalence research showed seropositivity for H6 viruses among occupational exposure workers in 19 provinces of China [10], and the analysis of veterinarians exposed to birds showed that the H6-specific antibody was significantly elevated in the United States [11]. In 2013, a H6N1 virus was isolated in Taiwan from a 20-year-old woman with symptoms, including fever, cough, headache, and muscle aches [12]. The study of $\mathrm{H6}$ viruses isolated from patients in Taiwan in the past 14 years suggests an elevated threat of $\mathrm{H6}$ viruses to human health [13]. These data indicate that in addition to HPAI H5 and H7 subtypes, H6 subtype IAVs might pose a potential threat to human health.

To prevent viral infections, alcohol is generally used to inactivate influenza viruses but has the disadvantage that it cannot be used for livestock or food. Therefore, chlorination, ozonation, and UV light are widely used for disinfection. However, there are some health concerns regarding the use of chemicals-based disinfection methods. For instance, residual chlorine in drinking water can cause the formation of potentially carcinogenic halogenated by-products [9]. In addition, ozonation can lead to excess concentrations of undesired by-products, such as bromate, which is a potential human carcinogen $[14,15]$. In contrast, sunlight or ultraviolet (UV) irradiation does not produce residual chemicals. UV rays can be classified by wavelength into UVA (320-400 nm), UVB (280-320 nm), and UVC ( $<280 \mathrm{~nm})$. A low-pressure UV (LP-UV) mercury lamp radiates a monochromatic peak wavelength $(254 \mathrm{~nm})$ and is used for common water treatment processes to remove and inactivate viral and microbial pathogens, mainly by damaging their genome [12]. In recent years, UV-light emitting diodes (UV-LEDs) have been developed as an alternative UV light emission source. While mercury lamps only emit light at one wavelength or over a broad range of wavelengths, UV-LEDs can irradiate light of a single wavelength without a filter and are capable of emitting light at multiple individual wavelengths [13]. LEDs are created by connecting $\mathrm{p}$ - and n-type semiconductors that move electrons into positively charged holes between these two materials. The wavelength of light will depend on the type of material used for the two semiconductors. Indium gallium nitride (InGaN) is a widely available semiconductor for highly efficient blue light or wavelengths in the UVA range. InGaN-based UVA-LEDs exhibit almost 50\% of external quantum efficiencies but cannot radiate deep UV wavelengths. Recently, aluminum gallium nitride (AlGalN) has been used as a semiconductor for deeper UV wavelengths from 250 to $350 \mathrm{~nm}$ and manufactured for many potential applications, including microbial disinfection. Kim D.K., et al. [16] demonstrated that irradiation by 266, 270, 275, and $279 \mathrm{~nm}$ UV-LEDs inactivated both gram-positive and gram-negative bacteria and yeast. They showed that a low WL UV-LED induced higher microbial reduction of both bacteria and yeasts than a 
high WL one, but there was no significant difference $(p>0.05)$. Meanwhile, Li Q.G., et al. [17] reported that a $265 \mathrm{~nm}$ UV-LED was more effective than a $280 \mathrm{~nm}$ UV-LED or LP-UV lamp for Escherichia coli inactivation. For the inactivation of bacteriophages, Kim D.K., et al. [18] reported that a $266 \mathrm{~nm}$ UVC-LED was more effective than a $279 \mathrm{~nm}$ UV-LED or LP-UV lamp. Sholtes K.A., et al. [19] reported that the microbial inactivation kinetics of the $260 \mathrm{~nm}$ UV-LED were not significantly different than those of the LP-UV lamp for E. coli and bacteriophages but were higher than LP-UV lamps for Bacillus atrophaeus spores. From these reports, low WL UV-LEDs around 260-266 nm would exhibit the highest microbial reduction among UV-LEDs and LP-UV lamps. We previously reported that irradiation by UVA (365 nm), UVB (310 nm), and UVC (280 nm)-LEDs inhibited the infectious titer of both IAV H1N1 and H5N1 subtypes [20]. In our study, we found that a UVC-LED with a peak WL of $280 \mathrm{~nm}$ showed the highest inactivation effect on IAVs among the UV-LEDs tested. However, we did not compare the inactivation effect of IAVs between UV-LEDs and LP-UV lamps, and how the peak WL of UV-LED is most effective for the inactivation of IAVs remains unclear. To investigate the highest inactivation effect of IAVs in this study, we irradiated virus suspensions of the H1N1 subtype using eight UV-LEDs with peak wavelengths of 365, 310, 300, 290, 280, 270, and $260 \mathrm{~nm}$ and measured the infection ratio using different host organisms, including Madin-Darby canine kidney (MDCK) cells and chicken embryonated eggs. In addition, we compared the inactivation effect of UV-LEDs with that of an LP-UV lamp. We found that the emission spectrum of UV-LEDs, which showed the highest inactivation effect among all treatments, strongly correlated with the absorbance spectrum of viral RNA. Therefore, we demonstrated that irradiation with the spectrum that strongly correlates with the absorption spectrum of viral RNA by the combination of different peak-wavelength UV-LEDs (hybrid UV-LED) enhanced the inactivation of both H1N1 and H6N2 subtypes.

\section{Materials and Methods}

\subsection{Cells and Virus Strains}

MDCK cells and the IAV H1N1 subtype (strain A/Puerto Rico/8/1934) were a kind gift from Professor Akio Adachi (Tokushima University Graduate School). The LPAI H6N2 subtype (A/Duck/Hong Kong/960/1980) was obtained from the Research Foundation for Microbial Diseases at Osaka University. MDCK cells were maintained at $37^{\circ} \mathrm{C}$ in a humidified atmosphere containing $5 \% \mathrm{CO}_{2}$ and cultured in Dulbecco's modified Eagle's medium (DMEM) supplemented with 5\% fetal bovine serum (AusGeneX, Oxenford, Australia) and 60 mg/mL kanamycin (Fujifilm Wako Pure Chemical Industries, Ltd., Tokyo, Japan). The virus suspension was prepared for irradiation experiments by propagating the IAV subtypes in 10-day-old chicken embryonated eggs (Ishii Poultry Agricultural Cooperative, Tokushima, Japan) for $48 \mathrm{~h}$ at $37^{\circ} \mathrm{C}$.

\subsection{UV-LEDs and LP-UV Lamp Irradiation of the Virus Suspensions}

Eight different peak wavelength UV-LEDs (Nichia, Tokushima, Japan) and an LP-UV lamp were used to irradiate the viral suspensions in this study (Table 1 and Figure 1). The three individual LEDs were on a printed circuit board (Audio-Q, Shizuoka, Japan, Figure 1a) and connected in series to a current-controlling single power source (PAS40-9, Kikusui Electronics Corp., Kanagawa, Japan). All UV-LEDs controlled the forward current (IF) by the power source for the adjustment of the fluence rate $\left(2.4 \mathrm{~mW} / \mathrm{cm}^{2}\right)$. A volume of $0.3 \mathrm{~mL}$ virus suspension with an infectivity titer of $1.92 \pm 0.13 \times 10^{7}$ $(\mathrm{H} 1 \mathrm{~N} 1)$ or $0.83 \pm 0.05 \times 10^{7}$ (H6N2) focus-forming units $(\mathrm{FFU}) / \mathrm{mL}$ was placed in a stainless steel cylinder cup (10 $\mathrm{mm}$ diameter and depth). The UV-LEDs and LP-UV lamp were emitted downward onto the surface of the solution for $2 \mathrm{sec}$ (fluence $=4.8 \mathrm{~mJ} / \mathrm{cm}^{2}$ ). The spectral fluence rates on the surface of samples were measured using an MCPD 3700A multiple wavelength photometer (Otsuka Electronics, Osaka, Japan) and PMA-12 Photonic multichannel analyzer (Hamamatsu photonics, Shizuoka, Japan). 
Table 1. Characteristics and Irradiating Conditions of the UV-light emitting diodes (UV-LEDs) and Low Pressure (LP)-UV Lamp Used in This Study.

\begin{tabular}{lccccc}
\hline Model Name & $\begin{array}{c}\text { Peak WL, } \\
\text { Spec }(\mathbf{n m})\end{array}$ & $\begin{array}{c}\text { Peak WL, } \\
\text { Measured }(\mathbf{n m})\end{array}$ & IF (A) & $\begin{array}{c}\text { Fluence Rate } \\
\left(\mathbf{m W} / \mathbf{c m}^{\mathbf{2}}\right)\end{array}$ & $\boldsymbol{R}_{\mathbf{A E}}$ \\
\hline NVSU233A-U365 & 365 & 366.6 & 0.042 & 2.4 & 0.2525 \\
NVSU234A-U310 & 310 & 310.9 & 0.136 & 2.4 & 0.3461 \\
MO-2257-U300 & 300 & 300.3 & 0.150 & 2.4 & 1.4436 \\
MO-2257-U290 & 290 & 288.5 & 0.133 & 2.4 & 8.8498 \\
NVSU234A-U280 & 280 & 280.5 & 0.160 & 2.4 & 21.4084 \\
MO-2257-U270 & 270 & 271.0 & 0.150 & 2.4 & 42.2429 \\
MO-2257-U260 & 260 & 261.0 & 0.350 & 2.4 & 68.5566 \\
UVC-S212T5 & 254 & 254.0 & - & 2.4 & 11.1486 \\
(LP-UV lamp) & & & & & \\
\hline
\end{tabular}

Note: $\mathrm{WL}$, wavelength; IF, forward current; $R_{\mathrm{AE}}$, correlation coefficient between absorbance spectrum of viral RNA and emission spectrum of UV irradiations; LP-UV lamp, mercury low pressure ultraviolet lamp.

(a)

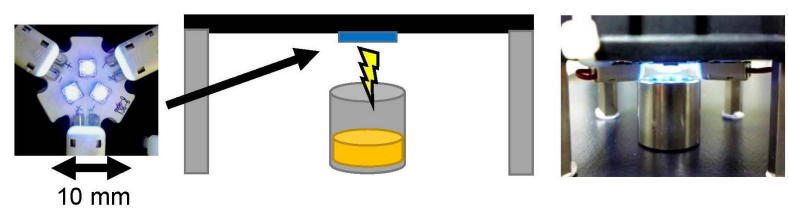

(b)

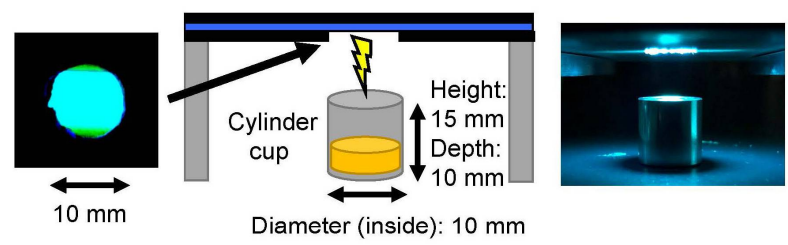

(c)

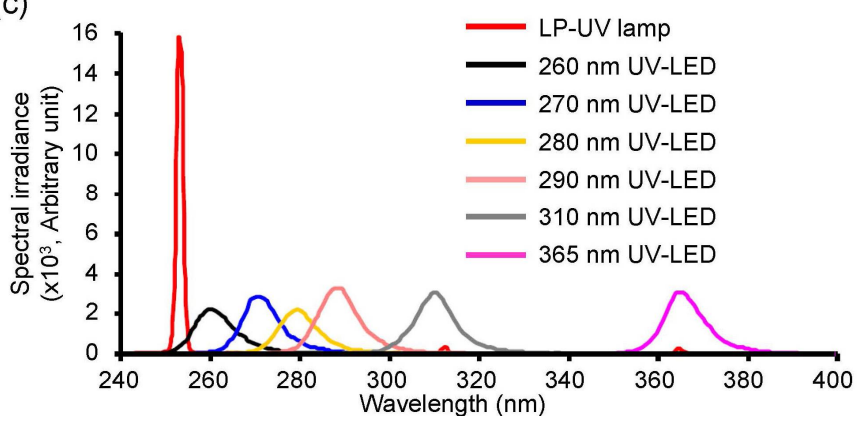

Figure 1. Irradiation system setup and emission spectrum of the UV-LEDs and low pressure-mercury (LP)-UV lamp used in this study. Photographs and schematic images of the UV-LEDs (a) and LP-UV lamp (b). (c) Emission spectrum of UV-LEDs. Detailed conditions of UV-LED irradiations are listed in Table 1.

\subsection{Infection of MDCK Cells and the Focus-Forming Assay}

MDCK cells were cultured in 48-well plates. At $13 \mathrm{~h}$ post-infection with UV-irradiated virus suspensions, the cells were fixed for $30 \mathrm{~min}$ at room temperature with buffered $4 \%$ paraformaldehyde and washed three times with phosphate-buffered saline (PBS). An unirradiated virus suspension was used as a control. Then, the cells were stained with a rabbit polyclonal antibody against the LPAI virus H5N2 subtype (strain A/duck Hong Kong/342/1978) to detect influenza virus antigens. This antibody recognizes the influenza virus NP and M1 proteins [21]. Antibody-binding viral proteins were detected with an Alexa Fluor 488-conjugated secondary antibody (Molecular Probes, Carlsbad, CA, USA) diluted 1:500 in PBS containing 1\% bovine serum albumin. An IX71N fluorescent microscope (Olympus, Tokyo, Japan) was used to observe the cells and count the FFUs. The effects of the LED irradiations on viral inactivation were determined by the infection ratio $\left(\log _{10}\right.$ FFU ratio), which was 
calculated as $\log _{10} \mathrm{FFU}$ ratio $=\log _{10}\left(N t / N_{0}\right)$, where $N_{t}$ is the FFU of the UV-irradiated sample, and $N_{0}$ is the FFU of the sample without UV irradiation.

\subsection{Infection of Embryonated Chicken Eggs}

After the irradiation of virus suspensions with the UV-LEDs and LP-UV lamp, the suspensions were diluted at 1:10 $1: 1: 10^{8}$ and infected into 10-day-old chicken embryonated eggs. Following incubation at $36^{\circ} \mathrm{C}$ for $72 \mathrm{~h}$, the allantoic fluids of the eggs were collected, clarified by centrifugation, and analyzed by HA assays. Viral titers were calculated as the $50 \%$ embryo infection dose $\left(\mathrm{EID}_{50}\right)$ as described by Guan J., et al. [22], and the effects of the LED irradiations were determined by the infection ratio $\left(\log _{10}\right.$ EID 50 ratio) calculated as $\log _{10} \mathrm{EID}_{50}$ ratio $=\log _{10}\left(N_{t} / N_{0}\right)$, where $N_{t}$ is the $\mathrm{EID}_{50}$ of the UV-irradiated sample, and $N_{0}$ is the EID 50 of the sample without UV irradiation.

\subsection{HA Assay}

The HA titer of the chorioallantoic fluid from the embryonated chicken eggs and the virus suspensions with or without UV irradiation were measured using a standard HA assay [23]. Two-fold serial dilutions of virus suspensions with or without UV irradiation were added to a round-bottomed 96-well plate and then mixed with $0.5 \%$ chicken red blood cells (Kohjin Bio Co., Ltd., Saitama, Japan). After incubation for $3 \mathrm{~h}$ at room temperature, HA titers were determined as the highest dilution at which complete agglutination was observed.

\subsection{RNA Extraction and RT-qPCR}

The damage to viral RNA by UV irradiation was measured by reverse transcription (RT)-quantitative real-time polymerase chain reaction (qPCR) as previously reported [20,24,25]. To isolate viral RNA from the viral suspension with or without UV irradiation, a QIAamp Viral RNA Mini Kit (Qiagen, Redwood City, CA, USA) was used according to the manufacturer's instructions. Specific RT of vRNA of H1N1 segment 6 was performed with tagged-primers (5'-GGCCGTCATGGTGGCGAATACTATAATGACTGATGGCCCGAGT-3') using Superscript III reverse transcriptase (Invitrogen, Carlsbad, CA, USA), as previously reported by Kawakami E., et al. [26]. A $5.5 \mu \mathrm{L}$ mixture containing viral RNA and $10 \mathrm{pmol}$ of the tagged primer was heated for $10 \mathrm{~min}$ at $65^{\circ} \mathrm{C}$ and then chilled immediately on ice for $5 \mathrm{~min}$. Next, $14.5 \mu \mathrm{L}$ of a preheated reaction mixture [ $4 \mu \mathrm{L}$ First Strand buffer (Invitrogen), $1 \mu \mathrm{L} 0.1 \mathrm{M}$ dithiothreitol (Invitrogen), $4 \mu \mathrm{L}$ dNTP mix (10 mM each, TaKaRa Bio, Shiga, Japan), $1 \mu \mathrm{L}$ Superscript III reverse transcriptase $(200 \mathrm{U} / \mu \mathrm{L}$, Invitrogen), $1 \mu \mathrm{L}$ RNasin Plus RNase inhibitor (40 U/ $\mu \mathrm{L}$, Promega, Fitchburg, WI, USA), and $3.5 \mu \mathrm{L}$ DEPC water] were added and incubated at $60^{\circ} \mathrm{C}$ for $1 \mathrm{~h}$. Real-time PCR was performed with a SYBER Green Premix Ex Taq II (Takara Bio) using a real-time PCR system Light cycler ${ }^{\circledR} 2.0$ Instrument (Roche, Mannheim, Germany). cDNA $(1.2 \mu \mathrm{L})$ was added to the qPCR reaction mixture [6 $\mu \mathrm{L}$ SYBER Green Premix Ex Taq II, $0.24 \mu \mathrm{L}$ forward primer (5'-GGCCGTCATGGTGGCGAAT-3', $10 \mu \mathrm{M}$ ), $0.24 \mu \mathrm{L}$ reverse primer (5'-ACATCACTTTGCCGGTATCAGGGT-3', $10 \mu \mathrm{M}$ ), and $4.32 \mu \mathrm{L}$ double-distilled water]. The reactions were heated at $95^{\circ} \mathrm{C}$ for 30 seconds followed by 40 cycles of a 10-second denaturing step at $95^{\circ} \mathrm{C}, 20$-second annealing step at $60^{\circ} \mathrm{C}$, and 15 -second extension step at $72{ }^{\circ} \mathrm{C}$.

\subsection{Calculation of Correlation Coefficients between the Absorbance Spectrum of Viral RNA and Emission Spectrum of $U V$-LEDs}

We were interested in investigating the relationship between the absorbance spectrum of viral RNA and the UV-LED emission spectra. After propagating the virus in 10-day-old chicken embryonated eggs for $48 \mathrm{~h}$ at $37^{\circ} \mathrm{C}$, allantoic fluids were precleared by centrifugation at $3300 \times g$ for $20 \mathrm{~min}$ followed by filtration through 0.45 imö pore filters. The viruses were then purified by centrifugation $(112,500 \times g$ for $2 \mathrm{~h}$ ) through PBS containing 20\% sucrose, as previously reported [21]. Virus pellets were resuspended in PBS and purified the viral RNA by a QIAamp Viral RNA Mini Kit (Qiagen). The purified viral RNA were checked by RT-PCR for segment 4 (supplementary Figure S1), as previously reported [20]. 
Although the absorbance spectrum of IAV RNA was measured with a UV-VIS spectrophotometer DU730 (Beckman Coulter, Brea, CA, USA), there is a difference in the spectral resolution between the spectrophotometer and the photonic multichannel analyzer (Hamamatsu photonics, Shizuoka, Japan) used for the measurement of emission spectra. For computation, it is often necessary to convert them to the same spectral resolution in the same range of wavelengths $(245 \mathrm{~nm}$ to $320 \mathrm{~nm})$. Therefore, in this work, the wavelength resolution of the spectrum was re-sampled into the same resolution $(0.1 \mathrm{~nm})$ using cubic spline interpolation. Further, the spectra were normalized by the maximum value in each spectrum. We used the measurement $R_{\mathrm{AE}}$ to investigate the relationship between the normalized absorbance spectrum of viral RNA and the normalized emission spectrum. $R_{\mathrm{AE}}$ was calculated using the following formula:

$$
R_{\mathrm{AE}}=\sum_{\lambda=b}^{B}|A(\lambda) \cdot S(\lambda)|^{2}
$$

where $A(\lambda)$ is the normalized viral RNA absorption spectrum, and $S(\lambda)$ is the normalized emission spectrum of the UV-LED or LP-UV lamp. The wavelength of the spectrum was used from $245 \mathrm{~nm}(\mathrm{~b})$ to $320 \mathrm{~nm}$ (B) for the calculation. For the calculation of $R_{\mathrm{AE}}$ of the $365 \mathrm{~nm}$ UV-LED, the maximum wavelength ranged up to $400 \mathrm{~nm}$ and was normalized by those of the other UV-LEDs. We used MATLAB R2017b software (The Mathworks, Natick, MA, USA) for the computation of $R_{\mathrm{AE}}$.

\subsection{Statistical Analysis}

Statistical analysis of differences was performed using ANOVA with Bonferroni's multiple comparison tests using Statview 5.0 software (SAS Institute Inc., Cary, NC, USA). The Student's t-test was used for paired data where appropriate. $p<0.05$ was considered statistically significant. Spearman's rank correlation test was used for the analysis of the association between two variables. For comparisons between two correlations, the correlation coefficient values were transformed into $\mathrm{z}$ scores by Fisher's $\mathrm{r}$ to $\mathrm{z}$ transformation and analyzed for statistical significance by determining the observed $\mathrm{z}$ test statistic.

\section{Results}

\subsection{Inactivation Effects of Irradiations by Different UV-LEDs and a Low-Pressure UV Lamp on the IAV H1N1 Subtype}

To determine the effects of UV irradiations on the IAV H1N1 subtype, we irradiated virus suspensions using UV-LEDs or an LP-UV lamp with an equal fluence rate $\left(2.4 \mathrm{~mW} / \mathrm{cm}^{2}\right)$ and duration $(2 \mathrm{sec})$ and infected MDCK cells and embryonated chicken eggs with these virus suspensions. Irradiation by $290-365 \mathrm{~nm}$ UV-LEDs did not affect the infection ratio, whereas the $260-280 \mathrm{~nm}$ UV-LEDs and LP-UV lamp decreased the ratio in both MDCK cells and embryonated chicken eggs (Figure 2). These results suggested that low fluence irradiations $\left(4.8 \mathrm{~mJ} / \mathrm{cm}^{2}\right)$ by $260-280 \mathrm{~nm}$ UV-LEDs showed an inactivation effect on the IAV H1N1 subtype in both host organisms. The lowering effect of UV irradiations on the infection ratio was correlated with those peak WLs, but the lowering effect on the infection ratio by the $260 \mathrm{~nm}$ UV-LED was significantly lower than that by the LP-UV lamp. 
(a)

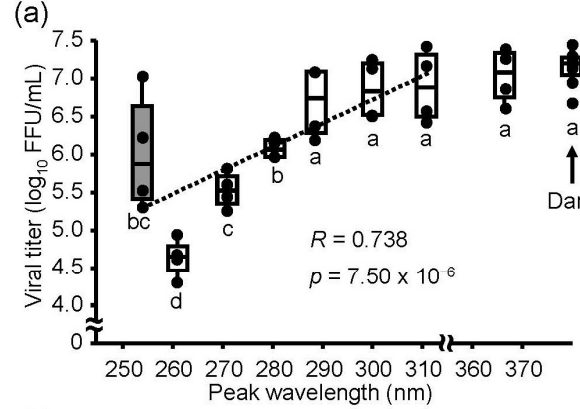

(b)

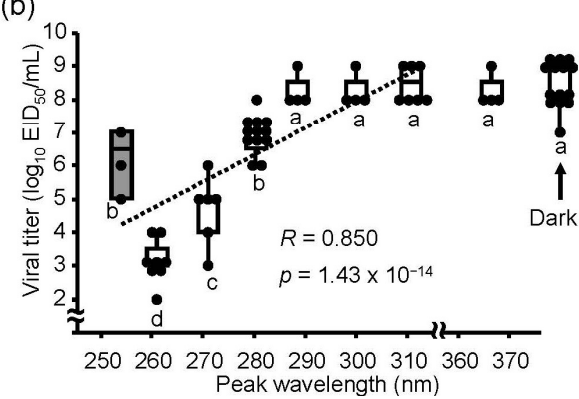

Peak wavelength $(\mathrm{nm})$

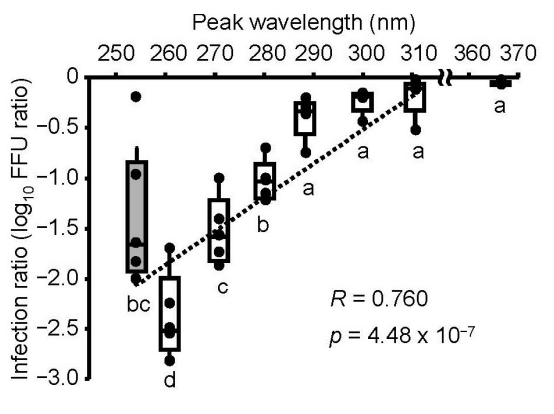

Peak wavelength $(\mathrm{nm})$

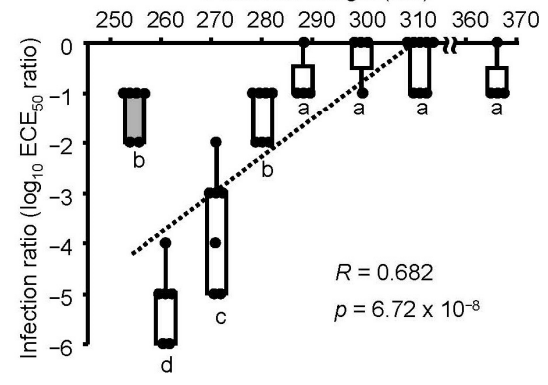

Figure 2. Inactivation effect of the UV-LEDs and LP-UV lamp on the influenza A virus H1N1 subtype. Viral suspensions of the H1N1 subtype (strain A/Puerto Rico/8/1934) were irradiated by different peak wavelength UV-LEDs (empty boxes) and an LP-UV lamp (gray box) at $4.8 \mathrm{~mJ} / \mathrm{cm}^{2}$ and infected into MDCK cells (a) or embryonated chicken eggs (b). Viral inactivation effects of these irradiations were determined by the difference of viral titers (left panels) and the $\log _{10}$ focus-forming assay (FFU) ratio and embryo infection dose $\left(\mathrm{EID}_{50}\right)$ ratio (right panels), as described in the Materials and Methods section. Each box plot shows the median (dark bar), values to the 1.5 interquartile ranges (whiskers), and 25 to 75 percentile ranges (box) ( $n=4-8, n=$ number of independent replicates). The dashed line shows the relationship between peak wavelengths and infection ratios. Different letters of the alphabet indicate a statistical difference $(p<0.05)$ compared with each other.

\subsection{Effect of UV-LED Irradiation on the HA Activity of Viral Suspensions}

HA plays an important role in the attachment of viruses to the cell surface of the host and release of the viral genome into the cytoplasm [27]. To determine the effect of UV-LEDs on the HA of the H1N1 subtype, we measured the HA activity of the virus suspension in the presence or absence of $4.8 \mathrm{~mJ} / \mathrm{cm}^{2}$ UV irradiation. None of the UV-LEDs or the LP-UV lamp altered the HA activities (Figure 3), suggesting that the UV irradiations at $4.8 \mathrm{~mJ} / \mathrm{cm}^{2}$ did not affect the binding capacity of IAV to host cells.

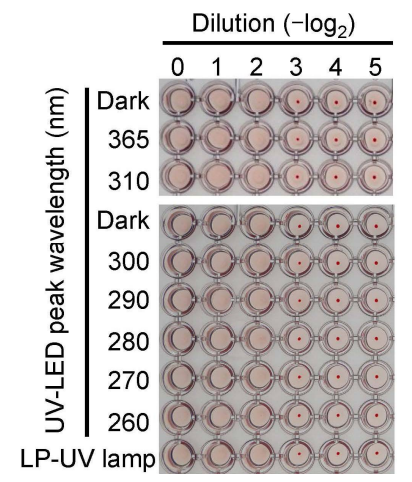

Figure 3. Effect of UV-LED irradiation on the hemagglutination titer. Viral suspensions of the H1N1 subtype (strain A/Puerto Rico/8/1934) were irradiated by UV-LEDs and the LP-UV lamp at $4.8 \mathrm{~mJ} / \mathrm{cm}^{2}$, and the hemagglutination activity was determined as described in the Materials and Methods section. 


\subsection{UV-LED- and LP-UV Lamp-Induced Damage to Viral RNA}

To measure the viral RNA damage induced by LED irradiation, we purified viral RNA from viral suspensions with or without UV-LEDs and LP-UV lamp irradiation at $4.8 \mathrm{~mJ} / \mathrm{cm}^{2}$, and performed strand-specific RT-qPCR, as described in the Materials and Methods section [20,24,25]. No effect was observed with 300-365 UV-LEDs, whereas 260-290 nm UV-LED and LP-UV lamp irradiation decreased the relative level of viral RNA, suggesting that 260-290 nm UV-LEDs could damage viral RNA (Figure 4a). Because the $260 \mathrm{~nm}$ UV-LED had the highest effects on both the disinfection ratio and damage of viral RNA, we assessed the correlation between the effect on the disinfection ratio and damage to viral RNA by the UV irradiations (Figure $4 \mathrm{~b}$ ). The ratios of damage to viral RNA by the UV irradiations were strongly correlated with the disinfection ratio in MDCK cells $(R=0.9524)$ and embryonated chicken eggs $(R=0.9102)$. These results suggest that the inactivation effects of irradiation by the UV-LEDs and LP-UV lamp are dependent on the damage of viral RNA, and we hypothesized that the wider range of emission spectra of UV-LEDs than that of the LP-UV lamp was an important factor for the inactivation of IAVs and induction of RNA damage.
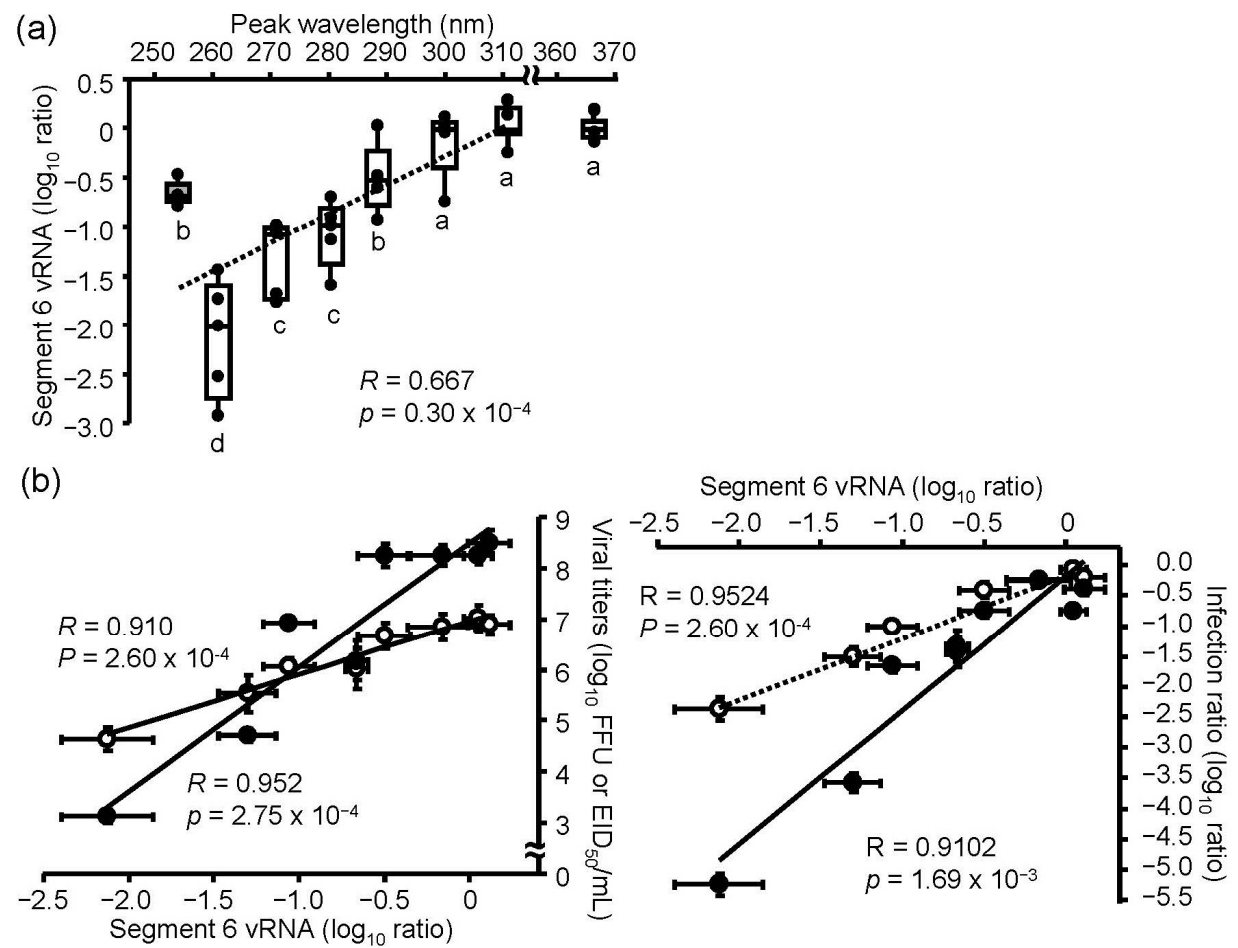

Figure 4. Effect of UV-LED irradiation on viral RNA. Viral suspensions of the H1N1 subtype (strain A/Puerto Rico/8/1934) were irradiated by UV-LEDs or an LP-UV lamp. Viral RNA damage was measured by vRNA (segment 6) strand-specific RT-qPCR, as described in the Materials and Methods section. (a) Damage of viral RNA by each UV irradiation. The dashed line shows the relationship between the peak wavelength and infection ratio. Different letters of the alphabet indicate a statistical difference $(p<0.05)$ between each other $(n=4-6, n=$ number of independent replicates). (b) The relationship between the inactivation effects and damage of viral RNA by each UV irradiation. Open circles and the dashed line indicate the data of the infection to MDCK cells. Filled circles and the solid line indicate the infection to embryonated chicken eggs. Viral inactivation effects of these irradiations were indicated by the difference of viral titers (left panels) and the $\log _{10}$ focus-forming assay (FFU) ratio and embryo infection dose ( $\left.\mathrm{EID}_{50}\right)$ ratio (right panels), as described in the Materials and Methods section. Results are displayed as means \pm SE. 


\section{4. $R_{A E}$ between the Absorbance Spectrum of Viral RNA and Emission Spectrum of UV Irradiations}

Next, we determined the relationship between the absorbance spectrum of viral RNA and the emission spectrum of UV irradiations. To investigate the relationship, we purified viral RNA from the chorioallantoic fluid in IAV-infected embryonated chicken eggs and measured the absorbance spectrum (Figure 5). We then calculated the $R_{\mathrm{AE}}$ between the spectrum and emission spectrum of the UV-LEDs and LP-UV lamp (Figure $5 \mathrm{~b}$ and Table 1). The $R_{\mathrm{AE}}$ scores of 300-365 nm UV-LEDs were lower than 1.5. In addition, the lower the peak WL of 260-290 nm UV-LEDs was, the higher the $R_{\mathrm{AE}}$ was. The $R_{\mathrm{AE}}$ score of the LP-UV lamp $\left(R_{\mathrm{AE}}=11.15\right)$ was lower than that of the $260 \mathrm{~nm}$ UV-LED $\left(R_{\mathrm{AE}}=68.56\right)$ and $270 \mathrm{~nm}$ UV-LED ( $\left.R_{\mathrm{AE}}=42.24\right)$ (Figure $5 \mathrm{~b}$ ). The correlation coefficient between the disinfection ratio and $R_{\mathrm{AE}}$ of $\mathrm{UV}$ irradiations was significantly higher than that between the disinfection ratio and peak WL of the irradiations (Figure 6 and Table 2). From these results, $R_{\mathrm{AE}}$ is a more important index for the inactivation of IAVs by UV irradiation than WL.

(a)

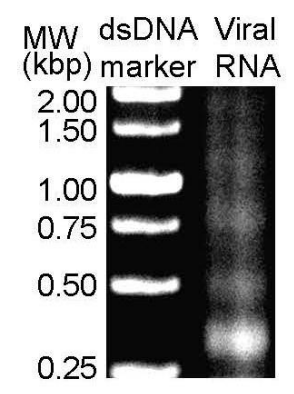

(b)

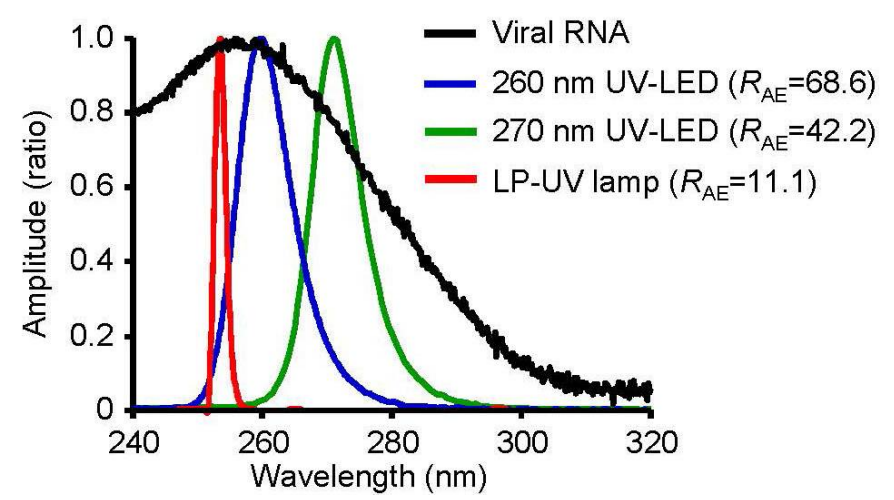

Figure 5. Absorbance spectrum of viral RNA and emission spectrum of UV irradiations. (a) A representative image of agarose gel electrophoresis for purified viral RNA. (b) Absorbance spectrum of viral RNA and emission spectrum of UV irradiations. $R_{\mathrm{AE}}$ score indicates the correlation coefficient between the absorbance spectrum of viral RNA and emission spectrums of UV irradiations.

(a)

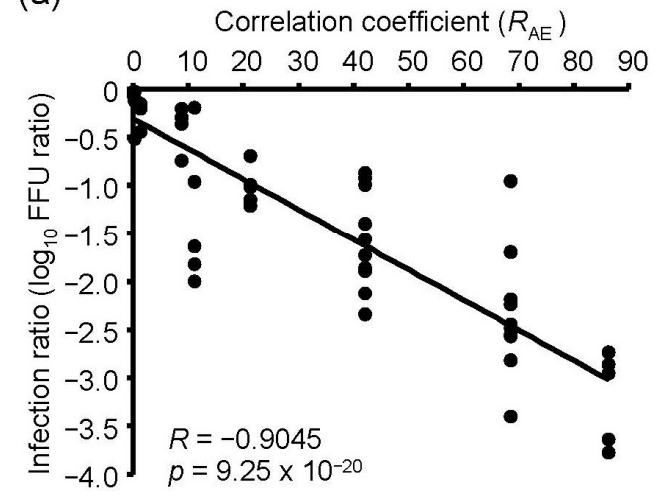

(b)

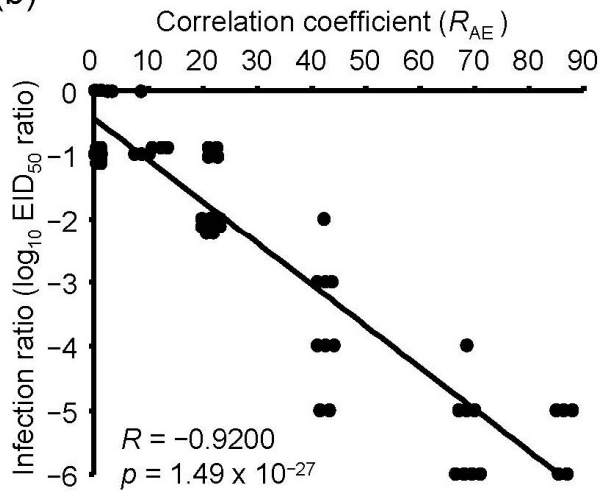

Figure 6. The relationship between the inactivation effects of UV irradiations and $R_{\mathrm{AE}}$ scores. Inactivation effects were measured by infection into MDCK cells (a) or embryonated chicken eggs (b) as host organisms. $R_{\mathrm{AE}}$ score indicates the correlation coefficient between the absorbance spectrum of viral RNA and emission spectrums of UV irradiations. 
Table 2. The Difference in Correlation Coefficients between the Disinfection Ratio and Peak Wavelength or $R_{\mathrm{AE}}$ of UV Irradiations.

\begin{tabular}{cccc}
\hline $\begin{array}{c}\text { Host Organism. } \\
\text { for Infection }\end{array}$ & $\begin{array}{c}\boldsymbol{R}_{\mathbf{N}} \text { (Disinfection Ratio - } \\
\text { Peak WL of UV Irradiations) }\end{array}$ & $\begin{array}{c}\boldsymbol{R}_{\mathbf{N}} \text { (Disinfection Ratio - } \\
\boldsymbol{R}_{\text {AE } \text { of UV Irradiations) }}\end{array}$ & $p$ Value \\
\hline MDCK cells & 0.760 & 0.9045 & 0.0488 \\
embryonated chicken eggs & 0.682 & 0.9200 & 0.000087 \\
\hline
\end{tabular}

$\mathrm{WL}$, wavelength; $R_{\mathrm{AE}}$, correlation coefficient between the absorbance spectrum of viral RNA and emission spectrum of UV irradiations; $R_{\mathrm{N}}$, natural number of correlation coefficients between the disinfection ratio and peak WL or $R_{\mathrm{AE}}$ of UV irradiations.

\subsection{Inactivation Effects of Hybrid UV-LED Irradiations on IAV H1N1 and H6N2 Subtypes}

To demonstrate an inactivation effect of UV irradiation with a higher $R_{\mathrm{AE}}$, we combined three different UV-LEDs (hybrid LED), including MO-2257-U270 (Table 1), MO-2257-U260 (Table 1), and one whose peak WL was $258.5 \mathrm{~nm}$, which was recently developed by Nichia (Tokushima, Japan). We simultaneously irradiated at $2.4 \mathrm{~mW} / \mathrm{cm}^{2}\left(0.8 \mathrm{~mW} / \mathrm{cm}^{2}\right.$ each UV-LED) (Figure $\left.7 \mathrm{a}, \mathrm{b}\right)$. The $R_{\mathrm{AE}}$ score of the hybrid UV-LED $\left(R_{\mathrm{AE}}=86.3\right)$ was higher than those of the other UV irradiations in this study (Figure 7b).

(a)

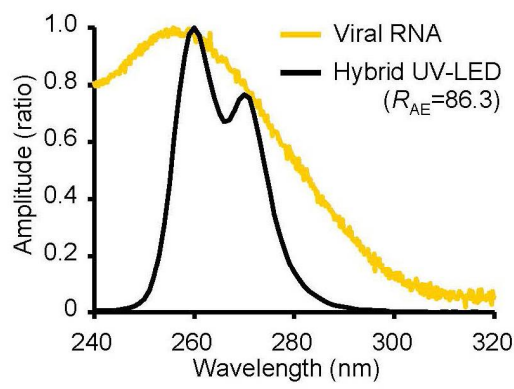

(c)

$\mathrm{H} 1 \mathrm{~N} 1$

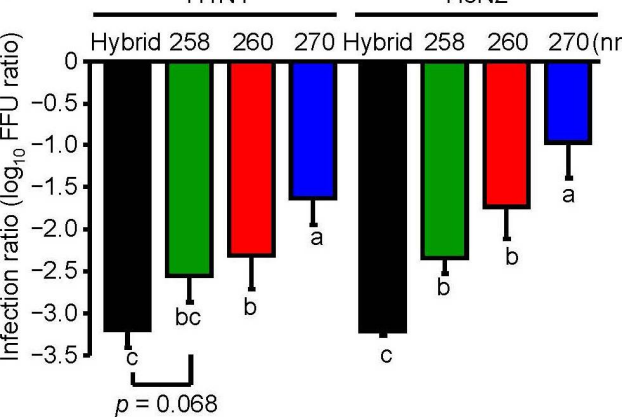

(b)

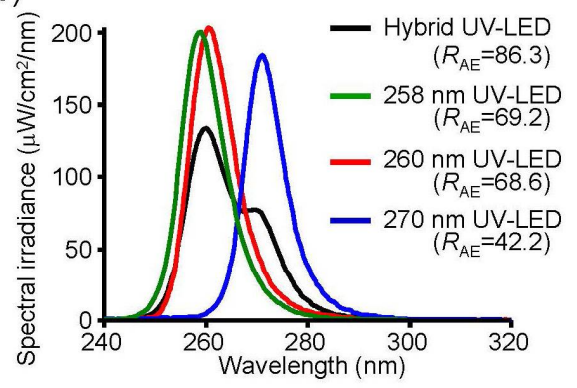

(d)

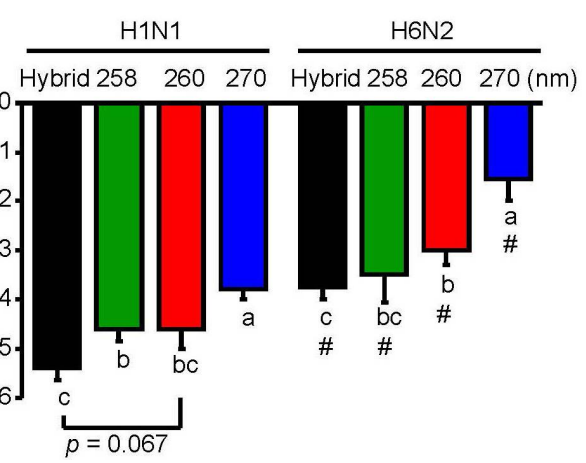

Figure 7. Inactivation effect of the hybrid UV-LED on influenza A virus H1N1 and H6N2 subtypes. (a) Absorbance spectrum of viral RNA and emission spectrum of hybrid UV-LED. (b) Emission spectrums of the hybrid UV-LED, $258 \mathrm{~nm}$ UV-LED, $260 \mathrm{~nm}$ UV-LED, and $270 \mathrm{~nm}$ UV-LED at $4.8 \mathrm{~mJ} / \mathrm{cm}^{2}$. $R_{A E}$ score indicates the correlation coefficient between the absorbance spectrum of viral RNA and emission spectrums of UV irradiations. Detailed conditions of the hybrid UV-LED were described in Section 3.5. (c,d) Inactivation effect of the hybrid LED on influenza A virus H1N1 and H6N2 subtypes. Viral suspensions of H1N1 (strain A/Puerto Rico/8/1934) or H6N2 (A/Duck/Hong Kong/960/1980) were irradiated by the UV-LEDs at $4.8 \mathrm{~mJ} / \mathrm{cm}^{2}$ and infected into MDCK cells. (c) or embryonated chicken eggs. (d). Results are displayed as means \pm SE $(n=5-8, n=$ number of independent replicates). Different letters of the alphabet indicate a statistical difference $(p<0.05)$ between each other. (\#) indicates $p<0.05$ vs. H1N1 subtype under the identical UV-LED irradiation.

To compare the inactivation effect of the hybrid UV-LED and $258 \mathrm{~nm}, 260 \mathrm{~nm}$, or $270 \mathrm{~nm}$ UV-LED on IAVs, we irradiated virus suspensions of both $\mathrm{H} 1 \mathrm{~N} 1$ and H6N2 subtypes and infected them into 
MDCK cells and embryonated chicken eggs. In infected MDCK cells, the hybrid LED had a significant $(p<0.05)$ or a moderate trend toward significantly $(p=0.068)$ higher inactivation effects on both H1N1 and H6N2 subtypes than the $258 \mathrm{~nm}, 260 \mathrm{~nm}$ or $270 \mathrm{~nm}$ UV-LED (Figure 7c). In infected embryonated chicken eggs, the hybrid LED showed a significant $(p<0.05)$ or a moderate trend toward significantly ( $p=0.067$ ) higher inactivation effect on H1N1 subtype than the $258 \mathrm{~nm}, 260 \mathrm{~nm}$, or $270 \mathrm{~nm}$ UV-LED, but the effect on H6N2 was not different between the hybrid LED and $258 \mathrm{~nm}$ LED (Figure 7d).

\section{Discussion}

In this study, we investigated the peak WL of UV-LEDs with the highest viral inactivation effects on IAV and compared the inactivation effect between the UV-LEDs and LP-UV lamp. The 260 nm UV-LED exhibited the highest effect among the UV-LEDs and LP-UV lamp at $4.8 \mathrm{~mW} / \mathrm{cm}^{2}$ for the inactivation of the H1N1 subtype infected into MDCK cells and chicken embryonated eggs. Our data are supported by two reports on the virucidal effects of irradiation on bacteriophages. Kim D.K., et al. [18] reported that the $266 \mathrm{~nm}$ UV-LED had a higher inactivation effect on non-envelope bacteriophages, including MS2, Q $\beta$, and $\Phi \times 174$, than the LP-UV lamp. In addition, Beck S.E., et al. [28] reported that the $260 \mathrm{~nm}$ UV-LED had a higher inactivation effect on MS2 bacteriophages than the LP-UV lamp. Furthermore, we demonstrated that the viral inactivation effects of UV-LEDs at $4.8 \mathrm{~mW} / \mathrm{cm}^{2}$ on IAV were not due to changes in the envelope protein HA. These data suggest that the beneficial effect of UV-LEDs compared with the LP-UV lamp is not due to envelope damage. Irradiation by the LP-UV lamp is well known to inactivate viral and microbial pathogens by mainly damaging their genome [12]. By vRNA strand-specific RT-qPCR, we found that irradiation with the $260 \mathrm{~nm}$ UV-LED damaged viral RNA to a greater extent than the LP-UV lamp (Figure 4a), and the damage to viral RNA by UV irradiation was strongly correlated to the inactivation effect (Figure 4b). Genomic RNA from MS2 bacteriophages has an absorbance spectrum between $240 \mathrm{~nm}$ and $300 \mathrm{~nm}$ [24], which is similar to the IAV RNA that we measured in this study (Figure 5b). These data are supported by a previous study that showed RNA damage by UV irradiation closely mirrored the loss of infectivity in MS2 bacteriophages [24]. The LP-UV lamp emits monochromatic UV irradiation at a wavelength of $254 \mathrm{~nm}$. In contrast, the $260 \mathrm{~nm}$ UV-LED irradiates at a wavelength near the LP-UV lamp but at a wider range of wavelengths (Figures 1c and 5b). From these data, we assessed whether the viral inactivation effect on IAVs by UV irradiation was due to the $R_{\mathrm{AE}}$ between the absorbance spectrum of viral RNA and the emission spectrum of the UV-LEDs and LP-UV lamp. Using in silico calculations, we found that the $R_{\mathrm{AE}}$ of the $260 \mathrm{~nm}$ UV-LED $\left(R_{\mathrm{AE}}=68.6\right)$ was higher than that of the LP-UV lamp $\left(R_{\mathrm{AE}}=11.1\right)$, and the $R_{\mathrm{AE}}$ of UV irradiations was strongly correlated to the viral inactivation effect by UV irradiations (Table 2). To increase the $R_{\mathrm{AE}}$ score, we developed a hybrid UV-LED $\left(R_{\mathrm{AE}}=86.3\right)$ by combining three different UV-LEDs (Figure 7a). Irradiation by the hybrid UV-LED had the highest inactivation effect on both H1N1 and H6N2 subtypes among the UV-LEDs and LP-UV lamp at $4.8 \mathrm{~mJ} / \mathrm{cm}^{2}$ fluence in this study (Figure 5). Beck S.E. and her colleagues previously showed that the inactivation effects of a combination of $260 \mathrm{~nm}$ and $280 \mathrm{~nm}$ UV-LEDs on MS2 bacteriophages, human adenovirus 2, and four human enteric viruses were not significantly different than that of the $260 \mathrm{~nm}$ or $280 \mathrm{~nm}$ UV-LED alone [28]. Because the fluence rate of the $280 \mathrm{~nm}$ UV-LED was higher than that of the $260 \mathrm{~nm}$ UV-LED [28], the combined irradiation might not be enough to increase the $R_{\mathrm{AE}}$ score. These results suggest that the peak WLs of UV-LEDs and the ratio of fluence rate of UV-LEDs combined may be important factors to increase the $R_{\mathrm{AE}}$ score.

We investigated the correlations between the viral inactivation effect by UV irradiations and the $R_{\mathrm{AE}}$ scores of the irradiations in this study. However, the correlations between the bactericidal effects and the scores remain to be elucidated. We previously reported that a combination of $365 \mathrm{~nm}$ UV-LED and LP-UV lamp irradiation exhibited a synergistic bactericidal effect on Vibrio parahaemolyticus that was dependent on the suppression of cyclobutene pyrimidine dimer (CPD) repair, such as recA- and lexA-mediated SOS responses. [29]. Our previous data were supported by Xiao Y., et al. [30] and Song K., et al. [31] who showed some synergistic inactivation effects on $E$. coli by the suppression of 
DNA repair using combined 265/365 nm UV-LED irradiations. However, some reports showed that the combination of $265 / 280 \mathrm{~nm}$ UV-LEDs had no synergistic effect on E. coli $[17,31]$. Irradiation by $365 \mathrm{~nm}\left(R_{\mathrm{AE}}=0.253\right)$ showed a minimal contribution to the increased $R_{\mathrm{AE}}$ score (Table 1$)$. These results suggest that the inactivation effects of combined UV-LEDs with different peak WLs may differ between bacteria and viruses.

We showed the loss of infectivity by UV-LED irradiations was due to damage to viral RNA, confirmed by RT-PCR, as previously reported in poliovirus- 1 and bacteriophages [20,24,25]. Determinate damage of viral RNA was not, however, defined in both those reports and this study. Pyrimidines are more sensitive bases against UV irradiation than purines [32]. UV irradiation generates not only DNA photoproducts such as CPDs, 6-4 pyrimidine-pyrimidone (6-4PP), and cytosine/thymine hydrate [32], but also several RNA photoproducts such as uracil cyclobutane dimer and uracil/cytosine hydrate [33]. We had determined irradiations by 260,270 , and $280 \mathrm{~nm}$ UV-LED at the same fluence $\left(4.8 \mathrm{~mJ} / \mathrm{cm}^{2}\right)$ in this study, and generated CPDs in herpes simplex virus 1 by dot-blot analysis using anti-CPDs antibody (data not shown). Petit-Frère C, et al. [34] reported that the photoproducts, including CPDs and 6-4PP, suppressed both DNA and RNA synthesis. From these reports, UV-LED-induced damage to viral RNA might be dependent on the formation of RNA photoproducts in IAVs. Unlike viral RNA, HA titer of H1N1 subtype was not changed by UV irradiations in this study (Figure 3). HA is a target for vaccines for IAVs because antibodies against HA are a major component of the human immune response and influenza vaccination [35]. Some studies showed that UV-inactivated viruses, including coronaviruses, were useful for the vaccines [36,37], but the studies about vaccines using UV-inactivated influenza viruses were scarcely reported [38]. Therefore, further work is needed to confirm whether UV-LED is useful for the generation of influenza inactivated vaccines.

We compared the viral inactivation effects of different UV-LEDs on various IAV subtypes, including H1N1 and avian H6N2, infected into MDCK cells and embryonated chicken eggs. In infected MDCK cells, both H1N1 and H6N2 subtypes were equally inactivated by UV-LED irradiations (Figure 7c,d). Similarly, Szeto W. et al. [39] demonstrated that H1N1 and H3N2 subtypes were equally inactivated by a vacuum-UV lamp for infection into MDCK cells. Meanwhile, in infected embryonated chicken eggs, the inactivation of H6N2 by UV-LED irradiation was reduced compared with the H1N1 subtype in this study. However, the crucial factors responsible for the different IAV strain-specific sensitivities to UV irradiation remain to be elucidated. Sutejo R., et al. [40] reported that the replication of the H1N1 subtype in chicken embryonic fibroblasts was lower than that of HPAI or LPAI. These data suggest that differences in the host responses to H1N1 and avian viruses may be a factor contributing to the subtype sensitivities to UV irradiations. Compared with IAVs and the other viruses, including MS2 coliphage, human adenovirus type 2 and human enteric viruses showed a lower sensitivity to the virucidal effect, by $260 \mathrm{~nm}$ or $280 \mathrm{~nm}$ UV-LED irradiation, respectively, than IAVs [19,28,41]. These data suggest that the sensitivities of various virus species and subtypes to UV-LED irradiation are different, and thus other strategies of UV-LED irradiation are necessary to inactivate UV-resistant subtypes.

In this study, we propose that the $R_{\mathrm{AE}}$ score should be an important factor for increasing the virucidal effect by UV-LED irradiation. However, we calculated the score using a range of 254-365 nm as the peak WL of the UV-LEDs and LP-UV lamp, but we should improve the $R_{\mathrm{AE}}$ score by generating more data using lower range WLs of the UV irradiations. Our study may contribute to preventing the spread of IAVs and avian flu viruses. Because the external quantum efficiencies of AlGaN-based UV-LEDs remain $<10 \%$, the development of higher quantum efficiencies is necessary for the application of viral inactivation in the near future.

Supplementary Materials: The following are available online at http://www.mdpi.com/2076-2607/8/7/1014/s1, Figure S1: Purification of viral RNA from allantoic fluids of mock- or H1N1 IAV-infected chicken embryonated eggs.

Author Contributions: Conceptualization, K.M., T.E., Y.K., and A.T.; methodology, K.M., E.T., T.S., T.U., T.D., and T.N.; software, K.M., E.T., and M.A.; validation, M.K. and K.M.; formal analysis, M.K., K.M., and T.E.; investigation, M.K., K.M., R.N.-N. and T.K.N.B.; resources, T.W., M.O., H.I., and K.T.,; data curation, K.M. and 
E.T.; writing-original draft preparation, M.K., K.M. and E.T.; writing-review and editing, K.M. and A.T.; visualization, K.M. and T.E.; supervision, A.T.; project administration, K.M. and A.T.; funding acquisition, T.N. and A.T. All authors have read and agreed to the published version of the manuscript.

Funding: This work was supported by JSPS KAKENHI Grant Numbers $18 \mathrm{H} 03040$ and $20 \mathrm{H} 01616$.

Acknowledgments: The excellent technical support of Hajime Fukuda, Koji Furuya, and Mutsumi Aihara (Tokushima University) is gratefully acknowledged. This study was supported by the Support Center for Advanced Medical Sciences, Tokushima University Graduate School of Biomedical Sciences.

Conflicts of Interest: The authors declare no conflict of interest.

\section{References}

1. Blut, A. Influenza virus. Transfus. Med. Hemother. 2009, 36, 32-39. [CrossRef]

2. Sato, R.; Okura, T.; Kawahara, M.; Takizawa, N.; Momose, F.; Morikawa, Y. Apical trafficking pathways of influenza A virus HA and NA via Rab17- and Rab23-positive compartments. Front. Microbiol. 2019, 10, 1857. [CrossRef]

3. Kumlin, U.; Olofsson, S.; Dimock, K.; Arnberg, N. Sialic acid tissue distribution and influenza virus tropism. Influenza. Other. Respir. Viruses 2008, 2, 147-154. [CrossRef]

4. Gamblin, S.; Skehel, J. Influenza hemagglutinin and neuraminidase membrane glycoproteins. J. Biol. Chem. 2010, 285, 28403-28409. [CrossRef]

5. Sawicka, R.; Siedlecki, P.; Kalenik, B.; Radomski, J.P.; Sączyńska, V.; Porębska, A.; Szewczyk, B.; Sirko, A.; Góra-Sochacka, A. Characterization of mAb6-9-1 monoclonal antibody against hemagglutinin of avian influenza virus $\mathrm{H} 5 \mathrm{~N} 1$ and its engineered derivative, single-chain variable fragment antibody. Acta. Biochim. 2017, 64, 85-92. [CrossRef] [PubMed]

6. DeJesus, E.; Costa-Hurtado, M.; Smith, D.; Lee, D.H.; Spackman, E.; Kapczynski, D.R.; Torchetti, M.K.; Killian, M.L.; Suarez, D.L.; Swayne, D.E.; et al. Changes in adaptation of H5N2 highly pathogenic avian influenza H5 clade 2.3.4.4 viruses in chickens and mallards. Virology. 2016, 499, 52-64. [CrossRef] [PubMed]

7. El-Shesheny, R.; Mostafa, A.; Kandeil, A.; Mahmoud, S.H.; Bagato, O.; Naguib, A.; Refaey, S.E.; Webby, R.J.; Ali, M.A.; Kayali, G. Biological characterization of highly pathogenic avian influenza H5N1 viruses that infected humans in Egypt in 2014-2015. Arch. Virol. 2017, 162, 687-700. [CrossRef] [PubMed]

8. Yan, Y.; Gu, J.Y.; Yuan, Z.C.; Chen, X.Y.; Li, Z.K.; Lei, J.; Hu, B.L.; Yan, L.P.; Xing, G.; Liao, M.; et al. Genetic characterization of H9N2 avian influenza virus in plateau pikas in the Qinghai Lake region of China. Arch. Virol. 2017, 162, 1025-1029. [CrossRef]

9. Fawell, J.; Robinson, D.; Bull, R.; Birnbaum, L.; Boorman, G.; Butterworth, B.; Daniel, P.; Galal-Gorchev, H.; Hauchman, F.; Julkunen, P.; et al. Disinfection by-products in drinking water: Critical issues in health effects research. Environ. Health. Perspect. 1997, 105, 108-109. [CrossRef]

10. Park, J.D.; Zheng, W. Human exposure and health effects of inorganic and elemental mercury. J. Prev. Med. Public. Health 2012, 45, 344-352. [CrossRef]

11. Kim, D.S.; Choi, K. Global trends in mercury management. J. Prev. Med. Public. Health 2012, 45, $364-373$. [CrossRef] [PubMed]

12. Delrue, I.; Delputte, P.L.; Nauwynck, H.J. Assessing the functionality of viral entry-associated domains of porcine reproductive and respiratory syndrome virus during inactivation procedures, a potential tool to optimize inactivated vaccines. Vet. Res. 2009, 40, 62. [CrossRef] [PubMed]

13. Bowker, C.; Sain, A.; Shatalov, M.; Ducoste, J. Microbial UV fluence-response assessment using a novel UV-LED collimated beam system. Water. Res. 2011, 45, 2011-2019. [CrossRef] [PubMed]

14. Gunten, V.U. Ozonation of drinking water: Part I. Oxidation kinetics and product formation. Water. Res. 2003, 37, 1443-1467. [CrossRef]

15. Gunten, V.U. Ozonation of drinking water: Part II. Disinfection and by-product formation in presence of bromide, iodide or chlorine. Water. Res. 2003, 37, 1469-1487. [CrossRef]

16. Kim, D.K.; Kim, S.J.; Kang, D.H. Bactericidal effect of 266 to $279 \mathrm{~nm}$ wavelength UVC-LEDs for inactivation of Gram positive and Gram negative foodborne pathogenic bacteria and yeasts. Food. Res. Int. 2017, 97, 280-287. [CrossRef]

17. Li, G.Q.; Wang, W.L.; Huo, Z.Y.; Lu, Y.; Hu, H.Y. Comparison of UV-LED and low pressure UV for water disinfection: Photoreactivation and dark repair of Escherichia coli. Water. Res. 2017, 126, 134-143. [CrossRef] 
18. Kim, D.K.; Kim, S.J.; Kang, D.H. Inactivation modeling of human enteric virus surrogates, MS2, Q $\beta$, and ФX174, in water using UVC-LEDs, a novel disinfecting system. Food. Res. Int. 2017, 91, 115-123. [CrossRef]

19. Sholtes, K.A.; Lowe, K.; Walters, G.W.; Sobsey, M.D.; Linden, K.G.; Casanova, L.M. Comparison of ultraviolet light-emitting diodes and low-pressure mercury-arc lamps for disinfection of water. Environ. Technol. 2016, 37, 2183-2188. [CrossRef]

20. Nishisaka-Nonaka, R.; Mawatari, K.; Yamamoto, T.; Kojima, M.; Shimohata, T.; Uebanso, T.; Nakahashi, M.; Emoto, T.; Akutagawa, M.; Kinouchi, Y.; et al. Irradiation by ultraviolet light-emitting diodes inactivates influenza a viruses by inhibiting replication and transcription of viral RNA in host cells. J. Photochem. Photobiol. B 2018, 189, 193-200. [CrossRef]

21. Daidoji, T.; Watanabe, Y.; Ibrahim, M.S.; Yasugi, M.; Maruyama, H.; Masuda, T.; Arai, F.; Ohba, T.; Honda, A.; Ikuta, K.; et al. Avian influenza virus infection of immortalized human respiratory epithelial cells depends upon a delicate balance between hemagglutinin acid stability and endosomal pH. J. Biol. Chem. 2015, 290, 10627-10642. [CrossRef]

22. Guan, J.; Chan, M.; VanderZaag, A. Inactivation of avian influenza viruses on porous and non-porous surfaces is enhanced by elevating absolute humidity. Transbound. Emerg. Dis. 2017, 64, 1254-1261. [CrossRef]

23. Choi, J.G.; Jin, Y.H.; Kim, J.H.; Oh, T.W.; Yim, N.H.; Cho, W.K.; Ma, J.Y. In vitro anti-viral activity of psoraleae semen water extract against influenza A viruses. Front. Pharmacol. 2016, 7, 460. [CrossRef]

24. Beck, S.E.; Rodriguez, R.A.; Hawkins, M.A.; Hargy, T.M.; Larason, T.C.; Linden, K.G. Comparison of UV-Induced Inactivation and RNA Damage in MS2 Phage across the Germicidal UV Spectrum. Appl. Environ. Microbiol. 2015, 82, 1468-1474. [CrossRef]

25. Simonet, J.; Gantzer, C. Inactivation of Poliovirus 1 and F-specific RNA Phages and Degradation of Their Genomes by UV Irradiation at 254 Nanometers. Appl. Environ. Microbiol. 2006, 72, 7671-7677. [CrossRef]

26. Kawakami, E.; Watanabe, T.; Fujii, K.; Goto, H.; Watanabe, S.; Noda, T.; Kawaoka, Y. Strand-specific real-time RT-PCR for distinguishing influenza vRNA, cRNA, and mRNA. J. Virol. Methods. 2011, 173, 1-6. [CrossRef] [PubMed]

27. Memczak, H.; Lauster, D.; Kar, P.; Lella, D.S.; Volkmer, R.; Knecht, V.; Herrmann, A.; Ehrentreich- Förster, E.; Bier, F.; Stöcklein, M.F.W. Anti-hemagglutinin antibody derived lead peptides for inhibitors of influenza virus binding. PLoS ONE 2016, 11, e0159074. [CrossRef] [PubMed]

28. Beck, S.E.; Ryu, H.; Boczek, A.L.; Cashdollar, L.J.; Jeanis, M.K.; Rosenblum, S.J.; Lawal, R.O.; Linden, G.K. Evaluating UV-C LED disinfection performance and investigating potential dual-wavelength synergy. Water. Res. 2016, 109, 207-216. [CrossRef]

29. Nakahashi, M.; Mawatari, K.; Hirata, A.; Maetani, M.; Shimohata, T.; Uebanso, T.; Hamada, Y.; Akutagawa, M.; Kinouchi, Y.; Takahashi, A. Simultaneous Irradiation With Different Wavelengths of Ultraviolet Light Has Synergistic Bactericidal Effect on Vibrio Parahaemolyticus. Photochem. Photobiol. 2014, 90, 1397-1403. [CrossRef]

30. Xiao, Y.; Chu, X.N.; He, M.; Liu, X.C.; Hu, J.Y. Impact of UVA pre-radiation on UVC DISINFECTION performance: Inactivation, repair and mechanism study. Water. Res. 2018, 141, 279-288. [CrossRef] [PubMed]

31. Song, K.; Taghipour, F.; Mohseni, M. Microorganisms inactivation by wavelength combinations of ultraviolet light-emitting diodes (UV-LEDs). Sci. Total. Environ. 2019, 665, 1103-1110. [CrossRef] [PubMed]

32. Szeto, W.; Yam, W.C.; Huang, H.; Leung, D.Y.C. The efficacy of vacuum-ultraviolet light disinfection of some common environmental pathogens. BMC Infect. Dis. 2020, 20, 127. [CrossRef]

33. Durbeej, B.; Eriksson, L.A. On the Formation of Cyclobutane Pyrimidine Dimers in UV-irradiated DNA: Why Are Thymines More Reactive? Photochem. Photobiol. 2003, 78, 159-167. [CrossRef]

34. Wurtmann, E.J.; Wolin, S.L. RNA Under Attack: Cellular Handling of RNA Damage. Crit. Rev. Biochem. Mol. Biol. 2009, 44, 34-49. [CrossRef] [PubMed]

35. Wei, C.J.; Crank, M.C.; Shiver, J.; Graham, B.S.; Mascola, J.R.; Nabel, G.J. Next-generation influenza vaccines: Opportunities and challenges. Nat. Rev. Drug. Discov. 2020, 19, 239-252. [CrossRef]

36. Iwata-Yoshikawa, N.; Uda, A.; Suzuki, T.; Tsunetsugu-Yokota, Y.; Sato, Y.; Morikawa, S.; Tashiro, M.; Sata, T.; Hasegawa, H.; Nagata, N. Effects of Toll-like receptor stimulation on eosinophilic infiltration in lungs of $\mathrm{BALB} / \mathrm{c}$ mice immunized with UV-inactivated severe acute respiratory syndrome-related coronavirus vaccine. J. Virol. 2014, 88, 8597-8614. [CrossRef] [PubMed]

37. Takasuka, N.; Fujii, H.; Takahashi, Y.; Kasai, M.; Morikawa, S.; Itamura, S.; Ishii, K.; Sakaguchi, M.; Ohnishi, K.; Ohshima, M.; et al. A subcutaneously injected UV-inactivated SARS coronavirus vaccine elicits systemic humoral immunity in mice. Int. Immunol. 2004, 16, 1423-1430. [CrossRef] 
38. Platt, R.; Vincent, A.L.; Gauger, P.C.; Loving, C.L.; Zanella, E.L.; Lager, K.M.; Kehrli, M.E., Jr.; Kimura, K.; Roth, J.A. Comparison of humoral and cellular immune responses to inactivated swine influenza virus vaccine in weaned pigs. Vet. Immunol. Immunopathol. 2011, 142, 252-257. [CrossRef]

39. Petit-Frère, C.; Clingen, P.H.; Arlett, C.F.; Green, M.H. Inhibition of RNA and DNA Synthesis in UV-irradiated Normal Human Fibroblasts Is Correlated With Pyrimidine (6-4) Pyrimidone Photoproduct Formation. Mutat. Res. 1996, 354, 87-94. [CrossRef]

40. Sutejo, R.; Yeo, D.S.; Myaing, M.Z.; Hui, C.; Xia, J.; Ko, D.; Cheung, P.C.F.; Boon-Huan, T.; Sugrue, R. Activation of Type I and III Interferon Signalling Pathways Occurs in Lung Epithelial Cells Infected With Low Pathogenic Avian Influenza Viruses. PLoS ONE 2012, 7, E33732. [CrossRef]

41. Woo, H.; Beck, S.E.; Boczek, L.A.; Carlson, K.; Brinkman, N.E.; Linden, K.G.; Lawal, O.R.; Hayes, S.L.; Ryu, H. Efficacy of inactivation of human enteroviruses by dual-wavelength germicidal ultraviolet (UV-C) light emitting diodes (LEDs). Water (Basel) 2019, 11, 1131. [CrossRef] [PubMed]

(C) 2020 by the authors. Licensee MDPI, Basel, Switzerland. This article is an open access article distributed under the terms and conditions of the Creative Commons Attribution (CC BY) license (http://creativecommons.org/licenses/by/4.0/). 